\title{
Analysis of Oncological Second Opinions in a Certified University Breast and Gynecological Cancer Center Regarding Consensus between the First and Second Opinion and Conformity with the Guidelines
}

\author{
Michael P. Lux ${ }^{a, d}$ Sonja Wasner ${ }^{a} \quad$ Julia Meyer ${ }^{a} \quad$ Lothar Häberle $^{a}$ Carolin C. Hack ${ }^{a}$ \\ Sebastian Jud $^{a} \quad$ Alexander Hein $^{a} \quad$ Marius Wunderle $^{a} \quad$ Julius Emons $^{a} \quad$ Paul Gass $^{a}$ \\ Peter A. Fasching ${ }^{a}$ Sainab Egloffstein ${ }^{b}$ Jessica Krebs ${ }^{c}$ Yesim Erim $^{c}$ \\ Matthias W. Beckmann a, Christian R. Loehberg ${ }^{a}$ \\ a Department of Gynecology, Erlangen University Hospital, University Breast Center and University Gynecological

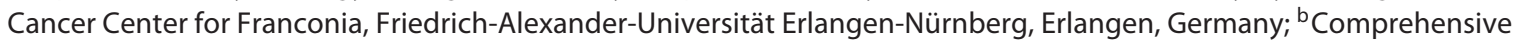 \\ Cancer Center Erlangen - European Metropolitan Region Nürnberg (CCC Erlangen-EMN), Erlangen, Germany; \\ 'Department of Psychosomatic and Psychotherapeutic, Erlangen University Hospital, Friedrich-Alexander-Universität \\ Erlangen-Nürnberg, Erlangen, Germany; ${ }^{\mathrm{d} B r e a s t}$ and Gynecological Cancer Center, Women's Hospital St. Louise, and \\ St. Josefs-Krankenhaus Salzkotten, St. Vincenz Hospital GmbH Paderborn, Paderborn, Germany
}

\section{Keywords \\ Second opinion · Breast cancer · Gynecological oncology · Certified cancer center - Oncology center · Guideline conformity}

\begin{abstract}
Introduction: Oncological second opinions are becoming increasingly important in the era of complex treatments and established certified cancer centers. Oncological guidelines with the highest levels of evidence are available, but these can only be effective to the extent that they are implemented. Therefore, we analyzed the effects of second opinions with regard to their agreement with first opinions and conformity with guidelines. Methods: In 164 patients with a diagnosis of breast cancer or gynecological malignancy who requested a second opinion, the first and second opinions, established at the interdisciplinary tumor conference, and conformity with the guidelines were evaluated. Results: The first opinion was not in agreement with the guidelines in $34.8 \%$ (15.2\% diagnosis, $12.8 \%$ surgical therapy, $13.4 \%$ systemic therapy, and 5.5\% radiotherapy), and the recommen-
\end{abstract}

dations were optimized in the second opinion in $56.7 \%$ (28.7\% diagnosis, $15.9 \%$ surgical therapy, $30.5 \%$ systemic therapy, and $8.5 \%$ radiotherapy). Conclusions: Oncological second opinions showed significant effects and one-third of first opinions were not in conformity with the guidelines. In a significant proportion of cases, the existing treatment plan was changed or supplemented to allow modern and individualized treatment approaches.

(c) 2020 S. Karger AG, Basel

\section{Introduction}

Choosing a treatment option can be a challenging decision for patients. This is particularly the case if the diagnosis is not clear, or if the alternative treatments are complicated and associated with risks or side effects. In this context, it is important to establish evidence-based and guideline-compliant indications. In the reality of health care, even today, in many cases, oncological treatment decisions are not made on an interdisciplinary basis during tumor conferences, but rather repre- 
sent (strictly speaking) an individual medical opinion [1].

Within the framework of the Federal Ministry of Health's National Cancer Plan in Germany, the development of evidence-based guidelines for cancer treatment and the establishment of certified cancer centers and oncology centers, with certification procedures supervised by the German Cancer Society (Deutsche Krebsgesellschaft, DKG), have promoted the optimization of qualityof-care for patients diagnosed with cancer; interdisciplinary collaboration, particularly in the field of oncology, is also encouraged [2]. The purpose of DKG certification of centers is to enable patients to benefit from optimized, interdisciplinary, and guideline-compliant diagnosis and treatment. In line with medical progress, the guidelines are to be compiled, regularly reviewed, and adapted to current developments when needed. On the one hand, these guidelines represent decision-making aids in the health care process, and on the other hand, they are an important element of quality control and quality indicators in certification procedures $[3,4]$.

With its certified Breast and Gynecological Cancer Center $[5,6]$ the Department of Gynecology at Erlangen University Hospital forms part of the institutional Oncological Center as well as the interdisciplinary Oncological Center of Excellence at the Comprehensive Cancer Center Erlangen - European Metropolitan Region Nürnberg (CCC Erlangen-EMN).

Within this framework, various organ-specific interdisciplinary tumor conferences, also at the certified Breast and Gynecological Cancer Center, have made it possible to provide care for a large number of individual oncological cases within short periods of time, and involved multidisciplinary specialist expertise for individual treatment recommendations. Ideally, the results of an interdisciplinary tumor conference can be based on complete and current staging findings and diagnostic results, the current status of a patient's clinical and physical findings, and her psychosocial situation, thus leading to a sound and evidence-based assessment of the overall situation which takes into account all relevant contributing factors.

In addition to treatment planning for the Department's own patients, the Department of Gynecology at Erlangen University Hospital is also increasingly providing advice to other institutions, family physicians, and outside patients, in connection with oncological second opinions. This has been the case since 2014, when the hospital began taking part in a pilot project organized by the statutory health-insurance scheme in Germany (Allgemeine Ortskrankenkassen, AOK) in accordance with the country's Social Security Code (Sozialgesetzbuch, SGB), and providing for medical second opinions on oncological diseases by an interdisciplinary tumor board.
In addition to medical counseling for patients, it can be recommended that a second medical opinion should be obtained before important treatment decisions are made. A second opinion is defined as obtaining a second treatment proposal after a suggested treatment has already been presented by another physician [7]. This second opinion can confirm the first opinion, or else offer alternatives and a discussion about the advantages and disadvantages of each treatment option in detail.

A position paper published by the DKG concerning the debate over medical second opinions encouraged patients and physicians to draw attention to the existence of institutions that provide a medical second opinion (certified oncology centers and organ cancer centers), further advisory services, and quality-assured sources of information (such as Cancer Aid's phone advice service "Infonetz Krebs," the cancer information service, patient guidelines, etc.) [8].

The pilot project mentioned above also included prospective scientific monitoring and analysis of various aspects of medical second opinions on oncological diseases [9]. The aim of this prospective survey in patients with breast cancer or gynecological malignancies was to analyze second opinions in relation to their frequency and characteristics, the consensus between the first and second opinions, and the conformity of the first opinion with guideline recommendations.

\section{Methods}

Study Design

The study analyzed second opinions in the Department of Gynecology at Erlangen University Hospital with regard to their consensus with first opinions, conformity with the guidelines, and avoidance of over- or undertreatment.

Using the written and/or digital patient files from the clinical information system (Soarian Clinicals ${ }^{\circledR}$ ) and data from the "CCC Erlangen-EMN Cancer Information" coordination office, patients were identified who received a second opinion with presentation at the interdisciplinary tumor conference of the certified Breast and Gynecological Cancer Center, Department of Gynecology, Erlangen University Hospital, in the period from June 2014 to September 2016, and the patients' clinical data were collected.

The patients generally had 2 ways of obtaining an oncological second opinion. Patients with breast cancer or a gynecological malignancy could either present directly for a second opinion during the special consultation hours at the Department of Gynecology at Erlangen University Hospital, or they could request a second opinion by phone through the "CCC Erlangen-EMN Cancer Information" service, which subsequently arranged for presentation of the case at the relevant interdisciplinary tumor conference.

During the period investigated, 488 patients received an oncological second opinion with presentation at the interdisciplinary tumor conference. A total of 167 agreed to participate in the study, 3 of whom had to be excluded as the case did not represent an oncological second opinion according to the following inclusion criteria: 
- An active request for an oncological second opinion

- An adult patient of any age

- A fully completed and signed declaration of consent

- The presence or diagnostic clarification of suspected breast cancer or gynecological malignancy

- Presentation at an interdisciplinary tumor conference in the Department of Gynecology at Erlangen University Hospital

The patient's age was defined as their age when they first contacted the hospital. The date of the initial diagnosis was determined on the basis of the date of the histological findings. If this was known from outside sources, that date was adopted. Staging of tumor entities was performed in accordance with the 7 th edition of the TNM classification [10].

\section{Assessment of Compliance with Guidelines}

Assessment of compliance with the guidelines was based on the available and currently valid guidelines on breast cancer and gynecological malignancies [11-18] by 2 medical experts, S. Wasner (Medical Training Assistant in gynecology and obstetrics and medical doctoral candidate) and M.P. Lux (specialist in gynecology and obstetrics with a focus on gynecological oncology).

\section{Consistency of Oncological First and Second Opinions}

The extent of agreement between the oncological first and second opinions was assessed using the 4 main pillars, i.e., diagnosis, surgery, systemic therapy, and radiotherapy, that were planned or had already been performed. Agreement was described using the following categories: "Yes" if there was agreement between the oncological first and second opinions, or "No" if there was no agreement. In addition, a potential lack of agreement could be classified as "not relevant" for the further course of the patient's treatment/ disease, or "not assessable" overall, e.g., due to a lack of data.

\section{Statistical Analysis}

The descriptive data were presented as absolute and relative frequencies and median (range). Logistic regression was used to analyze the influence of age and grading on adherence of the first opinion to the guidelines. Odds ratios (ORs) with corresponding $95 \%$ confidence intervals (CIs) and $p$ values were calculated for the predictors of logistic regression. All tests were bilateral, with a significance level of $\alpha=0.05$. The $R$ statistical package v3.4.0 (2017; $R$ Core Team, Vienna, Austria) and SPSS v24 were used for the analyses.

\section{Results}

\section{Description of the Study Population and Tumor \\ Entities}

The median age in the study group $(n=164)$ was 50.9 years (19.4-83.2 years) and all of the patients recruited were female. Most of the patients $(75.0 \%, n=123)$ had breast cancer. The second most common carcinoma was endometrial carcinoma $(9.8 \%, n=16)$. Other tumor entities included cervical carcinoma $(7.3 \%, n=12)$, ovarian carcinoma $(5.5 \%, n=9)$, vulvar carcinoma $(1.2 \%, n=2)$, and tubal carcinoma $(0.6 \%, n=1)$. One patient had 2 genital carcinomas (endometrial and cervical).

Analysis of the disease situation showed that $64.6 \%$ $(n=106)$ of the patients requested a second opinion in the adjuvant disease situation (curative), while 30.5\%
Table 1. Assessment of first-opinion conformity with the guidelines for patients with breast cancer or gynecological malignancies $(n=164)$

\begin{tabular}{lc}
\hline & $n(\%)$ \\
\hline Yes & $117(71.3)$ \\
Diagnosis & $81(49.4)$ \\
Surgery & $72(43.9)$ \\
Systemic therapy & $43(26.2)$ \\
$\quad$ Radiotherapy & \\
No & $25(15.2)$ \\
$\quad$ Diagnosis & $21(12.8)$ \\
Surgery & $22(13.4)$ \\
Systemic therapy & $9(5.5)$ \\
$\quad$ Radiotherapy & \\
Not relevant & $14(8.5)$ \\
$\quad$ Diagnosis & $37(22.6)$ \\
Surgery & $39(23.8)$ \\
$\quad$ Systemic therapy & $99(60.4)$ \\
$\quad$ Radiotherapy & \\
Not assessable & $8(4.9)$ \\
$\quad$ Diagnosis & $25(15.2)$ \\
$\quad$ Surgery & $31(18.9)$ \\
Systemic therapy & $13(7.9)$ \\
Radiotherapy &
\end{tabular}

( $n=50)$ sought a second opinion when the disease was already locally advanced or metastases were present (palliative). A further $4.9 \%$ of the patients $(n=8)$ were in the neoadjuvant situation.

\section{Assessment of Conformity of the Oncological First Opinion with the Guidelines}

A central aspect when comparing oncological first and second opinions was whether the first was in conformity with the guidelines. The medical evaluation showed that $34.8 \%$ of the patients $(n=57)$ had not received a guideline-compliant initial opinion in at least 1 of the 4 categories. Guideline conformity could not be assessed in $22.0 \%$ of the oncological first opinions received $(n=36)$, as they were incomplete. With regard to each category, "diagnosis" showed the widest divergence from the guidelines at $>15.2 \%$, followed by "systemic therapy" (13.4\%), and "surgical treatment" (12.8\%). Oncological first opinions in the category "radiotherapy" deviated from the guidelines in only $5.5 \%$ of cases. Further results for conformity of the oncological first opinions with the guidelines are presented in Table 1.

\section{Assessment of Changes in First-Opinion Treatment Recommendations after the Second Opinion}

Independently of guideline compliance, the frequency with which the recommendations on diagnosis and treatment given in the oncological first opinion altered after the second opinion was obtained from the interdisciplin- 
Fig. 1. First-opinion guideline compliance and change in treatment recommendations between the first and second opinions in 164 patients with breast cancer or gynecological malignancy.

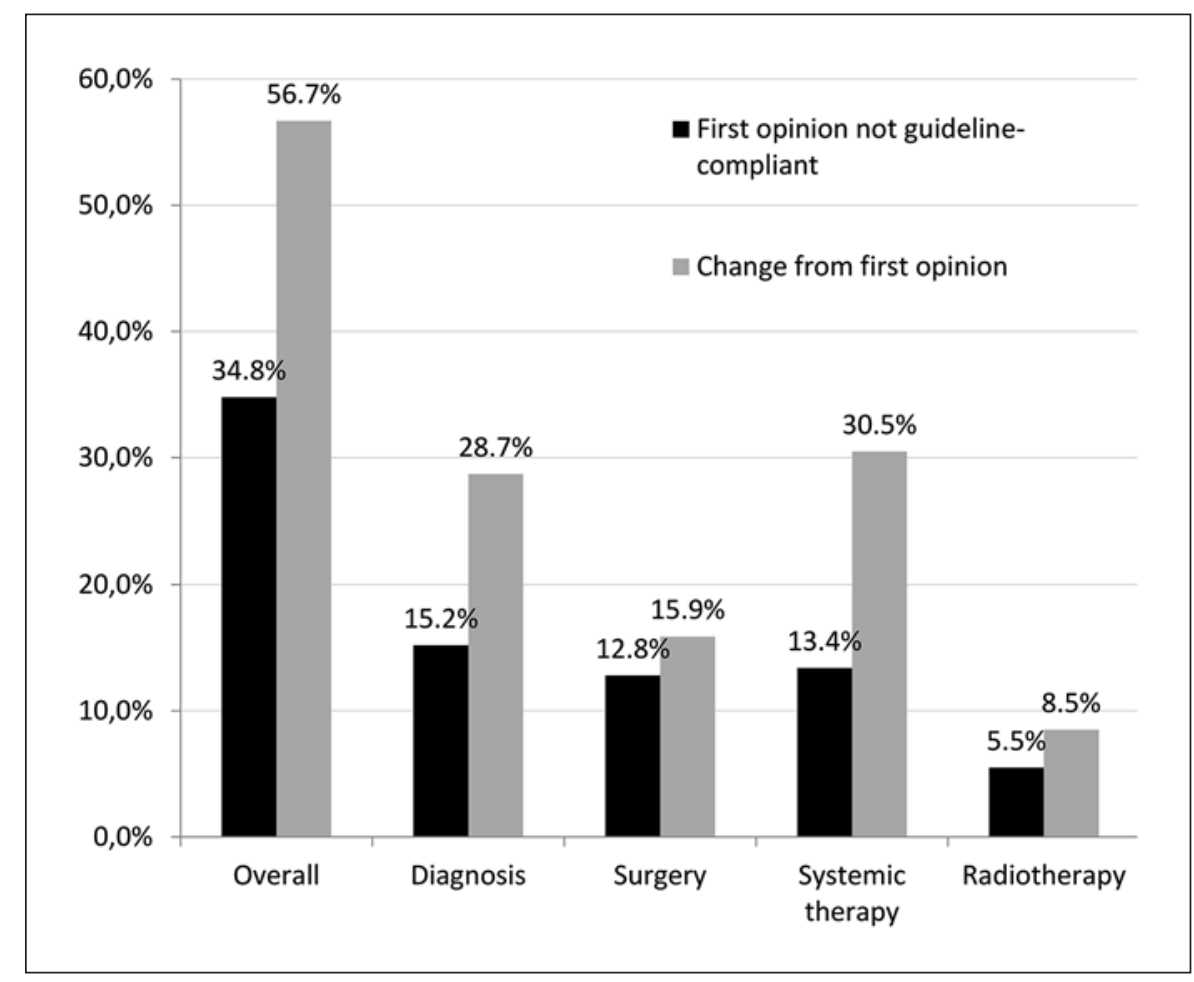

ary tumor conference was compared. The survey showed that more than half of the recommendations were optimized in the second opinion $(56.7 \%, n=93)$ (Fig. 1). The most frequent changes involved the recommendations on the type of systemic therapy $(30.5 \%, n=50)$.

\section{Avoidance of Over-and Undertreatment Due to the \\ Oncological Second Opinion}

Another aspect of oncological second opinions is that over- or undertreatment can be avoided by changes or corrections in the recommended therapy. For this reason, changes between the first and second opinions were classified more precisely (Table 2). In the majority of cases in which the second opinion altered the diagnosis, further diagnostic procedures were recommended (93.6\%). The majority of surgical and systemic treatments were modified by the second opinion and radiotherapy could usually be omitted once the second opinion had been obtained.

In addition to possible recommendations for changes in diagnosis or therapy in the oncological second opinion, it was also determined how often supplementary recommendations were added. In particular, an additional recommendation for genetic testing for suspected hereditary cancer, in accordance with the inclusion criteria of the German Consortium on Familial Breast and Ovarian Cancer, was made to $21.3 \%$ of the patients $(n=35)$. The oncological first opinions lacked any recommendation for genetic counseling and testing in this area, even
Table 2. Assessment of the type of change in the treatment recommendation between first and second opinions for patients with breast cancer or gynecological malignancy $(n=164)$

$n(\%)$

\section{Diagnosis}

Additional diagnosis recommended 44 (93.6)

Another diagnosis recommended

Surgery

Indication for treatment

Indication for omitting treatment

$4(15.4)$

Indication for changing treatment

$13(50.0)$

Systemic therapy

Indication for treatment

$7(14.0)$

Indication for omitting treatment

Indication for changing treatment

$10(20.0)$

$33(66.0)$

Radiotherapy

Indication for treatment

$3(21.4)$

Indication for omitting treatment

$8(57.1)$

Indication for changing treatment

$3(21.4)$

though risk factors were demonstrably present. Additional supportive measures were also recommended in $9.8 \%$ of the patients $(n=16)$.

In conclusion, 59 of 164 patients $(36.0 \%)$ decided to continue their treatment in the Department of Gynecology at Erlangen University Hospital after receiving the oncological second opinion. 
Analysis of Factors Potentially Influencing Treatment

Recommendations Resulting from the Oncological

First Opinion That Were Not Consistent with the

Guidelines

A matter of interest was also whether the guideline conformity of the treatment recommendation given in the oncological first opinion might have been dependent on specific factors connected with the patient or with the cancer itself. It is known both from everyday clinical practice and research studies that treatment recommendations are liable to diverge from the guidelines along with increasing patient age. In our study group, no significant correlation was observed between guideline-compliant treatment recommendations and age (OR 1.02; 95\% CI $0.99-1.06 ; p=0.14)$. Nor did tumor stage or the biological aggressiveness (grading) of the tumor have any significant influence on the conformity with the guidelines of the treatment recommendation given in the oncological first opinion (OR 0.76; 95\% CI 0.42-1.38; $p=0.36$ ).

Another issue was to assess how the oncological first opinion originated, i.e. whether it was given by a registered gynecologist, a medical practitioner, or a certified cancer center. Unfortunately, patients often gave ambiguous information, which rendered an advanced analysis of this aspect impossible. In the majority of patients $(78.6 \%, n=129)$, it was either not possible to elicit exactly who had determined the treatment plan $(69.5 \%, n=$ 114 ), or else the oncological first opinion had been established at a noncertified medical center $(9.1 \%, n=15)$. The oncological first opinion was verifiably given by a certified cancer center in only $21.3 \%$ of patients $(n=35)$.

\section{Discussion}

The establishment of a certified Breast and Gynecological Cancer Center at the Department of Gynecology at Erlangen University Hospital has made it possible to carry out diagnostic clarification of gynecological oncological diseases, and initiate individual, evidence-based therapy with standardization and optimization regarding time and quality. Through standardized case presentation, reproducible treatment procedures are recommended on the basis of internally developed treatment protocols, based on the treatment approaches described in the literature. Oncological second opinions are, of course, also presented and discussed in the interdisciplinary tumor conferences at each center $[2,5,6,19]$. In many cases, the question arises of whether surgery or systemic therapy (particularly chemotherapy) may be indicated in the specific disease situation (first opinion), or whether an indication for surgery or systemic therapy that has been established elsewhere should be confirmed, modified, or revoked in the oncological second opinion.
In approximately one-quarter of the cases (22\%), however, adequate information and findings for assessing the patient's overall medical situation or giving a detailed first opinion were not available. Not only the absence of individual findings is to be criticized here, but also the quality of the findings that were presented. CT findings are often only available as paper printouts, and/or are incomplete or of poor quality (i.e., in relation to contrast administration, layer thickness, etc.). Examinations can occasionally also be misleading or completely unusable due to delays in assessing aggressive tumor diseases. The diagnosis was altered in the second opinion in $28.7 \%$ of the patients in this study, with further imaging being recommended in most cases (93.6\%).

Histopathological findings are often very important for determining the treatment approach. In addition to the classic information about tumor staging, molecular markers are becoming increasingly important. For example, information on cell receptors such as Her2 status and other proteins is now indispensable for deciding current treatment approaches [20-24]. Studies in the USA have shown that, after reevaluation of histological material by a second pathologist, an initial diagnosis indicating surgery has to be revised in $7.8 \%$ of patients with breast cancer [25]. This particular study stated that a second opinion from a pathologist modified the diagnosis, treatment, or prognosis in as many as $80 \%$ of cases in a total of 340 patients. Often, the paraffin block inevitably has to be made available for reassessment. Information about tumor biology and the current tumor situation is extremely important for a comprehensive case assessment. This applies to the planning of surgical treatment, particularly the planning of modern, targeted systemic therapy.

An important aspect that we examined is whether the oncological second opinion alters the recommendation given in the oncological first opinion. Our study showed that, overall, the second opinion differed from the first in $56.7 \%$ of cases and was identical to the first opinion in $43.3 \%$.

Other recent studies conducted in German hospitals show a different picture with regard to the consensus of first and second oncological opinions. In a survey on patients diagnosed with early breast cancer at 86 hospitals in Germany, data on second opinions were collected for 419 patients [26]. It was found that the first and second opinions were identical and that no changes were made in $72.2 \%$ of the cases. One possible explanation for this might be that the study involved a questionnaire with the assessment being made by the patients themselves. In our study, by contrast, a complete case analysis was conducted by the physicians to compare the oncological first and second opinions.

With regard to surgery, there was a change in the oncological second opinion in $15.9 \%$ of the cases in our 
study (34.6\% were indications for implementation, $15.4 \%$ for omission, and $50.0 \%$ for a change in therapy). Comparable studies on breast cancer show similar rates of change in the surgical treatment strategy after an oncological second opinion, at approximately $20 \%[27,28]$. It was found that the recommendation changed from mastectomy to breast-conserving therapy in $20.2 \%$ of cases, and from breast-conserving therapy to mastectomy in $11.9 \%[28]$.

Surgical treatment as the first modality is not always reasonable, even if it initially appears so. Depending on the tumor entity, preoperative chemoradiotherapy or neoadjuvant systemic therapy can play an important role. Postoperative administration of systemic therapy or radiotherapy often depends on the outcome of the surgery. In general, however, a holistic individual therapy strategy should be developed at the start $[29,30]$. This long-term planning is important for patients, from both a psychooncological and a practical point of view.

More than one-third (34.8\%) of the oncological first opinions were not consistent with the guidelines in our study cohort. The positive influence of guideline-compliant treatment on recurrence-free survival (RFS) and overall survival (OS) has been investigated and published in numerous studies, particularly in connection with breast cancer [31-34]. For example, another German study on 371 patients with triple-negative breast cancer, which is characterized by aggressive growth and a poor prognosis, showed that the most important predictive factors for RFS and OS, in addition to nodal status and grading, were guideline-compliant surgical therapy, and adjuvant chemotherapy and radiotherapy [31]. In 66.8\% of patients with triple-negative breast cancer, however, $\geq 1$ (18\%) divergences from the guideline on "Early Detection, Diagnosis, Therapy, and Follow-up of Breast Cancer" (valid at the time) were noted $[11,12]$.

This makes the importance of guideline-based treatment recommendations very clear. In our study cohort, more than one-third of the patients would have been denied a guideline-based therapy recommendation if they had not had an oncological second opinion from a certified cancer center; they would thus also have been denied the potential chance of improved OS or a longer RFS.

Furthermore, the oncological first opinion was verifiably given in less than a quarter of patients by a certified cancer center, even though this result must be considered in the light of some limitations. There is a certain lack of information given by the patients where the oncological first opinion was obtained. Then again, this adds to the fact that there are still many obstacles which prevent patients from obtaining an oncological second opinion, e.g., manifold anxieties, perceived time pressure, and uncertainty triggered by an information overload. The biggest barrier keeping patients from seeking an oncological second opinion is the fear of compromising the patient-physician relationship. On the one hand, patients want to get the best possible cancer treatment but, on the other hand, they do not want to jeopardize the relationship with their attending physicians by seeking a second opinion and appearing to question their competence $[35,36]$. It is our opinion that patients should have the option of an oncological second opinion being openly offered to them by the attending physician. In this setting, patients could be encouraged to obtain an oncological second opinion and would not have a bad conscience about being disloyal to their physician.

A total of 59 patients $(36.0 \%)$ in our study elected to undergo further therapy at the Department of Gynecology, Erlangen University Hospital. In comparison, 65.8\% of the patients in the study by Clauson et al. [27] decided to have treatment carried out at the institute providing the oncological second opinion. In the study by Mellink et al. [37], only $16 \%$ of the patients had further treatment in the hospital providing the oncological second opinion. Overall, however, it has been observed that patients who obtain an oncological second opinion are often prepared to change the institution providing care. This may be due to being more satisfied with the oncological second opinion, dissatisfaction with the physician who gave the oncological first opinion, or other factors that led to them seeking the second opinion. Further analysis of these factors is therefore necessary.

\section{Conclusions}

In patients with breast cancer or a gynecological malignancy, obtaining a second opinion at a certified cancer center should be increasingly used as a way of confirming the treatment plan that has been chosen. A second opinion can allow critical examination of one's own approach in direct comparison with the constantly growing information available and the guidelines that are constantly being revised according to current treatment modalities. In addition, patients can be given greater assurance regarding the treatment approaches offered to them.

\section{Acknowledgement}

We would like to thank the staff involved in the study and all patients who participated in the study. The contribution of S.W. to this publication was made in partial fulfillment of the requirements for obtaining her medical doctoral degree. Parts of the research published here were used for her doctoral thesis at the Medical Faculty of Friedrich-Alexander-Universität Erlangen-Nürnberg (FAU), Germany. 


\section{Statement of Ethics}

All procedures performed in studies involving human participants were in accordance with the ethical standards of the institutional and/or national research committee and with the $1964 \mathrm{Hel}-$ sinki Declaration and its later amendments or comparable ethical standards. This article does not contain any studies with animals performed by any of the authors. Informed consent was obtained from all individual participants included in the study.

The study was approved on September 10, 2013 by the Ethics Committee of the Medical Faculty of Friedrich-Alexander-Universität Erlangen-Nürnberg, Germany (ethics vote No. 175_13B).

\section{Conflict of Interest Statement}

The authors have no conflicts of interest to declare.

\section{Funding Sources}

This work was supported by the Deutsche Krebshilfe (German Cancer Aid Foundation, No. 110533), Bonn (2013), and the Wolfgang Lutz Foundation, Nürnberg (2014), Germany.

\section{Author Contributions}

M.P.L.: protocol/project development and manuscript writing/ editing. S.W.: protocol/project development and data collection/ management. J.M.: statistical analysis and manuscript writing/editing. L.H.: statistical analysis. C.C.H., S.J.A., H.M.W., J.E., and P.G.: data collection and management. P.A.F.: quality control of data and algorithms. S.E., J.K., and Y.E.: data analysis. M.W.B.: protocol/ project development and coordination of funding. C.R.L.: manuscript writing/editing and data analysis/interpretation.

\section{References}

1 Ali J, Pieper D. Limited Data for Second Opinion Programs: a Systematic Review. Gesundheitswesen. 2017 Oct;79(10):871-4. German.

2 Beckmann MW, Adler G, Albers P, Bruns J, Ehninger G, Hauschild A, et al. Dreistufenmodell optimiert Behandlung unter Kostendeckung: Wie die künftigen Strukturen der onkologischen Versorgung in Deutschland aussehen sollten. Dtsch Arztebl Int. 2007 Nov; 104(44):A3004.

3 Kopp I, Encke A, Lorenz W. Leitlinien als Instrument der Qualitätssicherung in der Medizin Das Leitlinienprogramm der Arbeitsgemeinschaft Wissenschaftlicher Medizinischer Fachgesellschaften (AWMF). Bundesgesundhblatt Gesundhforsch Gesundhschutz. 2002; 45(3):223-33.

4 Wesselmann S. Evaluation of oncology clinical practice guidelines: the contribution of certified centers. Z Evid Fortbild Qual Gesundhwes. 2015;109(6):459-65. German.

5 Kowalski C, Ferencz J, Brucker SY, Kreienberg R, Wesselmann S. Quality of care in breast cancer centers: results of benchmarking by the German Cancer Society and German Society for Breast Diseases. Breast. 2015 Apr;24(2):118-23.

6 Wesselmann S, Beckmann MW, Winter A. The concept of the certification system of the German Cancer Society and its impact on gynecological cancer care. Arch Gynecol Obstet. 2014 Jan;289(1):7-12.

7 Hempel K, Siewert JR: "Second opinion" - attempt at establishing a definition. Chirurg. 1996;67:293-6. German.

8 DKG. [Internet] Qualitätsgesicherte Entscheidung zu Diagnostik und Therapie. Ein Positionspapier der Deutschen Krebsgesellschaft zur Diskussion um die ärztliche Zweitmeinung [cited 2015]. Available from: https:// www.krebsgesellschaft.de/positionen.

9 Krebs J, Wasner S, Egloffstein S, Lux MP, Morawa E, Beckmann MW, et al. Resilience, Fear of Progression and Psychosocial Distress in Patients with Breast Cancer and Gynecological Tumors Seeking a Second Opinion.
Psychother Psychosom Med Psychol. 2019 Jul;69(7):293-300. German.

10 Wittekind C. 2010 TNM system: on the 7th edition of TNM classification of malignant tumors. Pathologe. 2010 Sep;31(5):331-2. German.

11 Wöckel A, Festl J, Stüber T, Brust K, Krockenberger M, Heuschmann PU, et al. Interdisciplinary screening, diagnosis, therapy and follow-up of breast cancer. Guideline of the DGGG and the DKG (S3-Level, AWMF Registry Number 032/045-OL, December 2017) - Part 2 with recommendations for the therapy of primary, recurrent and advanced breast cancer. Geburtshilfe Frauenheilkd. 2018 Nov;78(11):1056-88. German.

12 Wöckel A, Festl J, Stüber T, Brust K, Stangl $\mathrm{S}$, Heuschmann PU, et al. Interdisciplinary screening, diagnosis, therapy and follow-up of breast cancer. Guideline of the DGGG and the DKG (S3-Level, AWMF Registry Number 032/045-OL, December 2017) - Part 1 with recommendations for the screening, diagnosis and therapy of breast cancer. Geburtshilfe Frauenheilkd. 2018 Oct;78(10):927-48. German.

13 Emons G, Steiner E, Vordermark D, Uleer C, Bock N, Paradies K, et al. Interdisciplinary diagnosis, therapy and follow-up of patients with endometrial cancer. Guideline (S3-Level, AWMF Registry Number 032/034-OL, April 2018) - Part 1 with recommendations on the epidemiology, screening, diagnosis and hereditary factors of endometrial cancer. Geburtshilfe Frauenheilkd. 2018 Oct;78(10): 949-71. German.

14 Emons G, Steiner E, Vordermark D, Uleer C, Bock N, Paradies K, et al. Interdisciplinary diagnosis, therapy and follow-up of patients with endometrial cancer. Guideline (S3-Level, AWMF Registry Number 032/ 034-OL, April 2018) - Part 2 with recommendations on the therapy and follow-up of endometrial cancer, palliative care, psycho-oncological/psychosocial care/rehabilitation/patient information and health- care facilities. Geburtshilfe Frauenheilkd. 2018 Nov;78(11):1089-109. German.

15 Hillemanns P, Friese K, Dannecker C, Klug S, Seifert U, Iftner T, et al. Prevention of cervical cancer: guideline of the DGGG and the DKG (S3 Level, AWMF Registry Number 015/027OL, December 2017) - Part 1 with introduction, screening and the pathology of cervical dysplasia. Geburtshilfe Frauenheilkd. 2019 Feb;79(2):148-59. German.

16 Hillemanns P, Friese K, Dannecker C, Klug $S$, Seifert U, Iftner T, et al. Prevention of cervical cancer: guideline of the DGGG and the DKG (S3 Level, AWMF Registry Number 015/027-OL, December 2017) - Part 2 on triage, treatment and follow-up. Geburtshilfe Frauenheilkd. 2019 Feb;79(2):160-76. German.

17 Schnürch HG, Ackermann S, Alt CD, Barinoff J, Böing C, Dannecker C, et al. Diagnosis, therapy and follow-up care of vulvar cancer and its precursors. Guideline of the DGGG and the DKG (S2k-Level, AWMF Registry Number 015/059, November 2015). Geburtshilfe Frauenheilkd. 2016 Oct;76(10):103549. German.

18 DKG. [Internet] Leitlinienprogramm Onko logie. S3-Leitlinie Diagnostik, Therapie und Nachsorge maligner Ovarialtumoren. Langversion 3.0. (AWMF Registry Number 032/ 035-OL, 2019). Available from: https://www. Leitlinienprogramm-onkologie.De/leitlinien/ovarialkarzinom.

19 Engelhardt M, Selder R, Pandurevic M, Moller M, Ihorst G, Waldschmidt J, Herget G, Wasch R. Multidisciplinary tumor boards: facts and satisfaction analysis of an indispensable comprehensive cancer center instrument. Dtsch Med Wochenschr. 2017; 142:e51-60. German.

20 Hartkopf AD, Müller V, Wöckel A, Lux MP, Janni W, Nabieva N, et al. Update breast cancer 2019 part 1 - implementation of study results of novel study designs in clinical practice in patients with early breast cancer. Geburtshilfe Frauenheilkd. 2019 Mar;79(3):256-67. German. 
21 Janni W, Schneeweiss A, Müller V, Wöckel A, Lux MP, Hartkopf AD, et al. Update breast cancer 2019 part 2 - implementation of novel diagnostics and therapeutics in advanced breast cancer patients in clinical practice. Geburtshilfe Frauenheilkd. 2019 Mar;79(3): 268-80. German.

22 Kolberg HC, Schneeweiss A, Fehm TN, Wöckel A, Huober J, Pontones C, et al. Update breast cancer 2019 part 3 - current developments in early breast cancer: review and critical assessment by an international expert panel. Geburtshilfe Frauenheilkd. 2019 May; 79(5):470-82. German.

23 Schütz F, Fasching PA, Welslau M, Hartkopf AD, Wöckel A, Lux MP, et al. Update breast cancer 2019 part 4 - diagnostic and therapeutic challenges of new, personalised therapies for patients with early breast cancer. Geburtshilfe Frauenheilkd. 2019 Oct;79(10):1079-89. German.

24 Welslau M, Hartkopf AD, Müller V, Wöckel A, Lux MP, Janni W, et al. Update breast cancer 2019 part 5 - diagnostic and therapeutic challenges of new, personalised therapies in patients with advanced breast cancer Geburtshilfe Frauenheilkd. 2019 Oct;79(10): 1090-9. German.

25 Staradub VL, Messenger KA, Hao N, Wiley EL, Morrow M. Changes in breast cancer therapy because of pathology second opinions. Ann Surg Oncol. 2002 Dec;9(10):982-7.
26 Cecon N, Hillen MA, Pfaff H, Dresen A, Groß SE. Why do newly diagnosed breast cancer patients seek a second opinion? - Second opinion seeking and its association with the physician-patient relationship. Patient Educ Couns. 2019 May;102(5):998-1004.

27 Clauson J, Hsieh YC, Acharya S, Rademaker AW, Morrow M. Results of the Lynn Sage Second-Opinion Program for local therapy in patients with breast carcinoma. Changes in management and determinants of where care is delivered. Cancer. 2002 Feb;94(4):889-94.

28 Morrow M, Jagsi R, Alderman AK, Griggs JJ, Hawley ST, Hamilton AS, et al. Surgeon recommendations and receipt of mastectomy for treatment of breast cancer. JAMA. 2009 Oct; 302(14):1551-6.

29 Schulz-Wendtland R, Dankerl P, Dilbat G, Bani M, Fasching PA, Heusinger K, et al. Evaluation of newly adapted clip marker system in ultrasound-guided core needle biopsy for suspicion of breast cancer. Geburtshilfe Frauenheilkd. 2013 Nov;73(11):1135-8. German.

30 Schulz-Wendtland R, Dankerl P, Bani MR, Fasching PA, Heusinger K, Lux MP, et al. Evaluation of a marker clip system in sonographically guided core needle biopsy for breast cancer localization before and after neoadjuvant chemotherapy. Geburtshilfe Frauenheilkd. 2017 Feb;77(2):169-75. German.

31 Schwentner L, Wolters R, Koretz K, Wischnewsky MB, Kreienberg R, Rottscholl R, et al. Triple-negative breast cancer: the impact of guideline-adherent adjuvant treatment on survival-a retrospective multi-centre cohort study. Breast Cancer Res Treat. 2012 Apr; 132(3):1073-80.
32 Hébert-Croteau N, Brisson J, Latreille J, Rivard M, Abdelaziz N, Martin G. Compliance with consensus recommendations for systemic therapy is associated with improved survival of women with node-negative breast cancer. J Clin Oncol. 2004 Sep;22(18):368593.

33 Varga D, Wischnewsky M, Atassi Z, Wolters R, Geyer V, Strunz K, et al. Does guidelineadherent therapy improve the outcome for early-onset breast cancer patients? Oncology. 2010;78(3-4):189-95.

34 Wöckel A, Kurzeder C, Geyer V, Novasphenny I, Wolters R, Wischnewsky M, et al. Effects of guideline adherence in primary breast cancer-a 5-year multi-center cohort study of 3976 patients. Breast. 2010 Apr;19(2):120-7.

35 Peier-Ruser KS, von Greyerz S. Why do cancer patients have difficulties evaluating the need for a second opinion and what is needed to lower the barrier? A qualitative study. Oncol Res Treat. 2018;41(12):769-73.

36 Hillen MA, Medendorp NM, Daams JG, Smets EM. Patient-driven second opinions in oncology: a systematic review. Oncologist. 2017 Oct;22(10):1197-211.

37 Mellink WA, Henzen-Logmans SC, Bongaerts $\mathrm{AH}$, Ooijen BV, Rodenburg CJ, Wiggers TH: Discrepancy between second and first opinion in surgical oncological patients. Eur J Surg Oncol. 2006 Feb;32(1):108-12. 